\title{
MODELING SIMPLE EXPERIMENTS OF BIOCHAR EROSION FROM SOIL
}

\author{
A Thesis \\ Presented to the Faculty of the Graduate School \\ of Cornell University \\ In Partial Fulfillment of the Requirements for the Degree of \\ Master of Science
}

by

Chaozi Wang

May 2013 
(C) 2013 Chaozi Wang 


\begin{abstract}
Biochar is often promoted as an amendment to improve soil quality. However, researchers have recently noted that biochar and similar substances preferentially erode from soil, which may reduce its effectiveness. Identifying the erosion mechanisms may help develop strategies for retaining biochar in soil. To investigate the role of raindrop impact biochar erosion, we applied the Hairsine-Rose erosion model to small-scale experiments that simulated rainfall on a simple biochar-soil mixture. The Hairsine-Rose model simulated the biochar concentrations in runoff well for the early part of the experiments but under-predicted the concentrations for longer times. After the simulated rainfall experiments we found that biochar content increased with depth in the soil column from $1 \%$ near the surface to $8 \%$ in underlying soil layer; similar distributions have been observed for soil, which drives upwards diffusion. By superimposing the Wallach diffusion model on the Hairsine-Rose model we were able to simulate biochar concentrations at both short and long times. We speculate that the relatively dense sand particles are displacing the biochar and we are investigating this further. Our findings suggest that long-term sequestration of biochar in soil is unlikely in soils or parts of the landscape with limited infiltration capacity.
\end{abstract}




\section{BIOGRAPHICAL SKETCH}

Chaozi Wang was born in Beijing, the capital of China, in Sep. 9th 1989 and grown up there until she came to Ithaca. Chaozi Wang began to love Mathematics at 7 years old, love Physics at 13 , love Chemistry at 14 , love geography at 15 , and love biology at 16 . And she loves all these disciplines until now.

The time she graduated from her undergraduate university, Beijing Normal University, in Resources Science and Engineering, she found that the cross-disciplinary research in Soil and Water Lab in the Department of Biological and Environmental Engineering, Cornell University is just the crosses all the disciplines she loves.

She really enjoyed studying physical process (erosion) of bio-material (biochar) by doing Chemistry experiments and solving math equations to deal with important geographic problem (soil amendment and carbon sequestration).

She will do more research in Soil and Water Lab for her PhD. 


\section{ACKNOWLEDGMENTS}

I want to thank Professor M. Todd Walter for coming up with such an interesting project for me to work on, for patiently answering my bunch of questions from the day he became my advisor until now, for giving me a lot of suggestions in choosing courses, modifying experiment, analyzing data, finding a good model, and writing, especially writing the thesis, for letting me feel free to speak out my thoughts and discuss problems with him. I real enjoy working with him and being his student.

I want to thank Professor Jean-Yves Parlange for helping me find the right way to do the experiment, for always sitting at his office and willing to answer my questions, for teaching me the physical meaning of the transport equations, and for giving me very quick response whenever I send him an email. He makes me feel free to explore the unknown things and apply complicated methods, because he can always find a way to solve my problems.

I want to thank Professor Bin Gao, Sara Storrer, Erik Rasmussen, Chris Berry, and Kyle Delwiche for helping me get started with the experiment.

I want to thank Xing Wang, Luyan Sun, and Xiaoya Cheng for helping with the rainfall part of my experiment.

I want to thank Shree Giri for helping me find ways to collect the data I want and thank Doug Caveney for making and fixing experimental units for me. 
I want to thank Lauren McPhillips, Sheila Saia, Larry D. Geohring, Steve Pacenka and Christine Baver for helping me finding things and getting familiar with lab B72 and B68.

I want to thank my parents for giving me life and not preventing me to come to Cornell University to study, although I'm their precious only child.

I want to thank my boyfriend, Pu Wang, for being such an excellent elder brother, who gives me a lot of guidance and is always willing to answer my all kinds of questions, and tolerate my all kinds of silly thoughts and behavior. 


\section{TABLE OF CONTENTS}

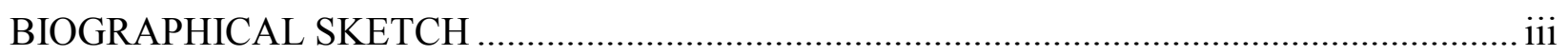

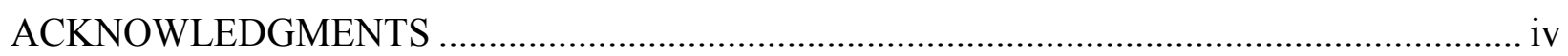

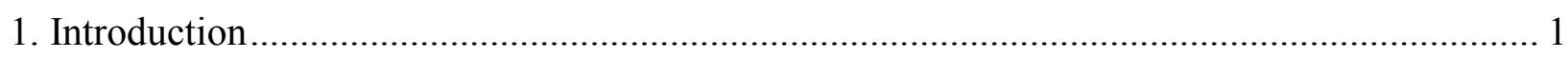

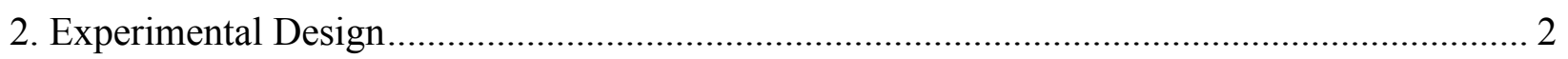

3. Hairsine-Rose Model Description.................................................................................. 5

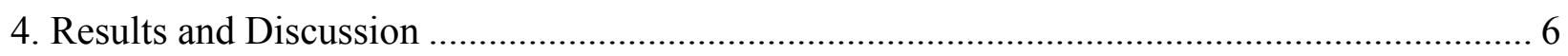

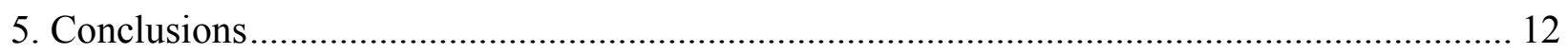

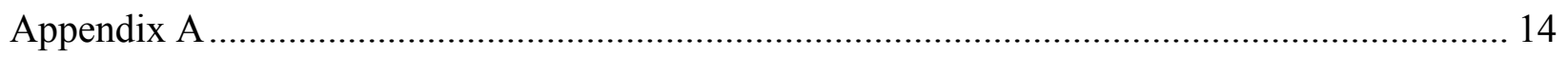

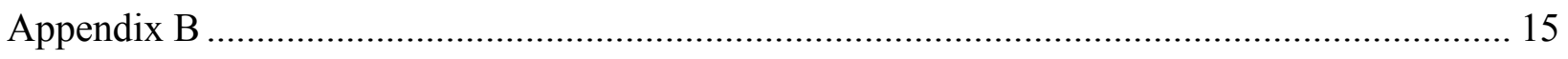

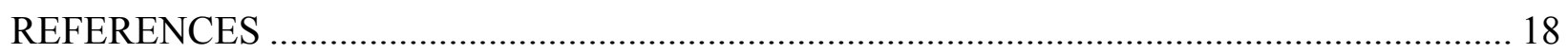




\section{Introduction}

Recently, biochar, also named bio-char, agrichar, and agri-char, and similar to charcoal, black carbon, and pyrogenic carbon, has been popular as a soil amendment because it has been shown to have many beneficial impacts on soil quality. These include: improved biological nitrogen fixation and nutrient retention and bioavailability (Glaser et al., 2002; Chan et al., 2007; Rondon et al., 2007), reduced plant availability of pesticides (Yu et al., 2009; Kookana, 2010), immobilization of phytotoxic heavy metals (Beesley et al., 2010; Uchimiya et al., 2010), improved plant resistance to pathogens (Elad et al., 2010), decreased non-point source nitrogen and phosphorous pollution (Lehmann et al., 2006). Biochar has also been found to be a potentially effective remedy to polycyclic aromatic hydrocarbon-contaminated soil (Beesley et al., 2010; Chen and Yuan, 2011). Amending soils with biochar is also promoted as a way to sequester carbon in the soil (Lehmann et al., 2006; Lehmann, 2007). However, the specific impacts on soil can vary for biochar produced from different sources or under different pyrolysis conditions (Singh et al., 2010; Uchimiya et al., 2010).

Cheng et al. (2008), Nguyen et al. (2008), Cheng and Lehmann (2009), Nguyen et al. (2010) and Major et al. (2010) speculate that large amounts of biochar are lost to storm runoff. But few researchers have investigated biochar erosion mechanisms. Rumpel et al. (2006a) measured the black carbon content along a slope and showed that black carbon tends to be eroded down-slope. In another study, Rumpel et al. (2006b) found more evidence that black carbon was preferentially eroded from the soil; specifically, black carbon content in eroded sediments collected at the outlet of the watershed was twice that found in the original soil. Rainfall experiment on meterscale plots with black carbon deposited on the surface illustrated the importance of splash 
erosion on black carbon loss (Rumpel et al., 2009). Indeed, although there are carbon fluxes associated black carbon loss, e.g. $\mathrm{CO}_{2}$ emissions, erosion appears to be the largest mechanism of black carbon loss and it is poorly quantified in current models (Foereid et al., 2011).

Perhaps the main reason why biochar is such a popular soil remedy is that it is a potentially affective way to sequester carbon (Lehmann, 2007). This is because it is very stable as compared to biomass (Lehmann, 2007). Also its fabrication can substitute fossil fuel burning as a power source, which is the primary anthropogenic carbon source to the atmosphere (Lehmann et al., 2006; Lehmann, 2007). Furthermore, biochar benefits soil fertility and crop productivity, which may attract farmers to apply it to soil (Lehmann et al., 2006).

However, preferential erosion may limit the potential benefits of amending soils with biochar, the underpinning processes of which are poorly understood (Rumpel et al., 2006a; Rumpel et al., 2006b; Rumpel et al., 2009; Major et al., 2010; Foereid et al., 2011). To begin to address this knowledge gap, we carried-out small scale experiments to isolate the biochar erosion process during rainfall-runoff conditions. We predicated our experiments on the hypothesis that biochar particles behave similarly to fine sediments in the rainsplash erosion process (see Heilig et al., 2001 and Gao et al., 2003 and 2005 for similar experimental studies with fine sediments).

\section{Experimental Design}

One part ground-biochar $(<250 \mu \mathrm{m})$ was saturated by mixing with enough deionized water. We used a vacuum pump to remove air trapped in the biochar suspension to ensure a saturated state when it is mixed into the sand matrix. More deionized water and the suspended biochar were 
mixed with nine parts sand to obtain a simple, well-mixed, saturated, biochar-amended soil. The soil was packed into a $7.6 \mathrm{~cm}$ diameter and $10.6 \mathrm{~cm}$ tall plexiglass column with 4 holes at the same height $(3.9 \mathrm{~cm})$ placed evenly around the column (Figure 1) and leveled utilizing a shaking table, and excess water was poured off (set-up adopted from Gao et al. (2003; 2004; 2005).

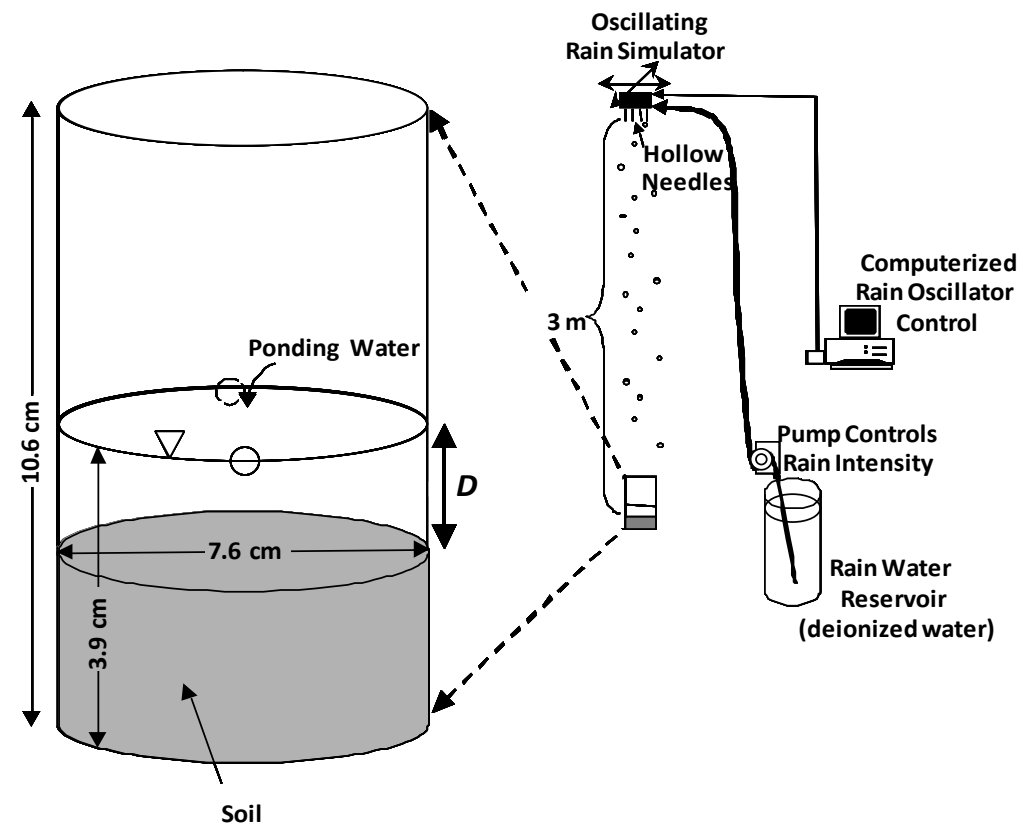

Figure 1. Experiment set-up, adopted from Gao et al. (2003; 2004; 2005)

After measuring the rainfall rate, we protected the study area from rain with an umbrella, and setup the soil column. Ponding water was added carefully following the process described by Heilig et al. (2001), but the ponding depth varied slightly between different experiments.

We collected $0.5 \mathrm{ml}$ runoff samples from the ponded water using a pipette. The first sample was extracted before removing the umbrella. Then we removed the umbrella, collected samples every $15 \mathrm{~s}$ initially and, as the runoff became visually less biochar laden, we lengthened the sampling interval to $30 \mathrm{~s}, 2 \mathrm{~min}, 5 \mathrm{~min}, 30 \mathrm{~min}$ and $1 \mathrm{hr}$; the decision to change the sampling time during 
the experiment was made qualitatively by the researcher operating the pipette. Both rainfall rate and ponding depth were measured before and after the erosion process, we used the average rates and depths in our model (Table 1).

In suspension the biochar particles tended to flocculate, which made it difficult to measure concentrations by spectrometry as Heilig et al. (2001) and Gao et al. (2003; 2005) did for clay. Biochar concentration of each runoff sample was acquired by the difference between the weight of the empty cuvette and the cuvette plus oven dried sample $\left(60^{\circ} \mathrm{C}\right.$ to constant weight).

We also did four separate experiments: (1) for determining soil moisture and soil bulk density, (2) initial and (3) final fractions of biochar in soil, and (4) visually verifying the depletion of biochar in the shield layer. For (1) we placed a known volume of soil-biochar mixture in Petri dish and obtained the wet weight minus the Petri dish. Then we dried it at $105{ }^{\circ} \mathrm{C}$ for $72 \mathrm{hr}$, and got the dry weight plus Petri dish until the weight stabilized. We used the wet and dried masses and known volume to determine the soil moisture and wet and dry bulk densities. For (2) we divided the pre-experimental soil into two layers, dried them at $105^{\circ} \mathrm{C}$ for $24 \mathrm{hr}$ in weighed crucibles, weighed the dry weight plus crucibles, combusted them at $950{ }^{\circ} \mathrm{C}$ for $3 \mathrm{hr}$, and got the residual weight plus crucible until the weight stabilized with continued combustion. We determined the carbon content by the difference between the masses before and after combustion. For (3) we divided a soil column after a 4-hr rainfall into a shield layer and 5 approximately 0.6-cm underlying layers, conducted the same drying, weighing and combusting procedure as in (2). Since a small part of sand is combustible and a small part of biochar is incombustible, we used a sample of pure dry sand and a sample of pure dry biochar to be control in the drying, weighing, 
and combusting procedure, and acquired the accurate proportion of biochar by solving a simple system of equations (Appendix A). For (4) we replaced the dark-colored sand in the main experiment with white sand and videoed and photographed the soil during and after the rainfall event.

\section{Hairsine-Rose Model Description}

Since the biochar we are considering is composed of small, light-weight particles, we adopted the simple form of the Hairsine-Rose model (Hairsine and Rose, 1991) developed by Heilig et al. (2001) for erosion experiments similar to ours:

$$
\begin{aligned}
\frac{d c_{b}}{d t} & =\frac{1}{D}\left[\frac{a P}{I}(1-H)-P c_{b}\right] \\
H & =1-\exp \left(-\frac{9 a P}{10 M_{s}^{*}} t\right)
\end{aligned}
$$

where $c_{b}$ is the concentration of biochar in the runoff $\left[\mathrm{M} \mathrm{L}^{-3}\right], t$ the time $[\mathrm{T}], D$ the runoff depth, i.e. ponding water depth $[\mathrm{L}], a$ the soil detachability $\left[\mathrm{M} \mathrm{L}^{-3}\right], P$ the rainfall rate $\left[\mathrm{L} \mathrm{T}^{-1}\right], H$ the fraction of the completely shielding shield layer, and $M_{S}^{*}$ the total deposited mass of sand per unit soil surface area at which full shielding occurs $\left[\mathrm{M} \mathrm{L}^{-2}\right]$. The first term in the brackets of (1) represents the ejection of biochar from the soil and the second term in the brackets is the removal of biochar via runoff. This form of the model is based on two assumptions: first, all the ejected biochar particles are transported from the soil column by rainfall-runoff while all the ejected sand particles settle onto the surface (described in Eq.1) and, second, deposited sand forms the shield layer, which accumulates until a point where no underlying biochar or sand can be ejected (expressed by Eq. 2). 
To simplify comparisons among experiments with slightly different conditions, we utilized three dimensionless variables and the dimensionless model suggested by Heilig et al. (2001):

$$
\begin{gathered}
C_{R}=c_{b} \frac{D}{M_{b}^{*}}, T=t \frac{P}{D}, \lambda=\frac{a}{10} \frac{D}{M_{b}^{*}} \\
C_{R}(T)=\frac{\lambda}{1-\lambda}[\exp [(1-\lambda) T]-1] \exp (-T)
\end{gathered}
$$

where $M_{b}^{*}$ is the total mass of eroded biochar per unit surface area $\left[\mathrm{ML}^{-2}\right]$, and $C_{R}$ and $T$ are dimensionless concentration of biochar and time, respectively.

\section{Results and Discussion}

Interestingly, our experimental data showed that, unlike the clay experiments of Heilig et al. (2001) and Gao et al. (2005), that the biochar concentrations remained elevated throughout the experiment (symbols in Figure 2). This suggests that the "shield" layer does not effectively restrict erosion of the biochar deeper in the soil and we could not determine $M_{b}^{*}$ as the cumulative biochar eroded during each experiment (as done by Heilig et al., 2001). Therefore, we calibrated both $a$ and $M_{b}^{*}$ to curve-fit the Hairsine-Rose model to the early part of the experiment under the assumption that rainsplash erosion would dominate the biochar-erosion process during this period (solid lines in Figure 2, Table 1). Specifically, we fitted $M_{b}^{*}$ to make all the measured data from the six experimental runs, expressed in dimensionless form, follow the same distribution. We then fitted $a$ to make the six modeled curves overlap. 


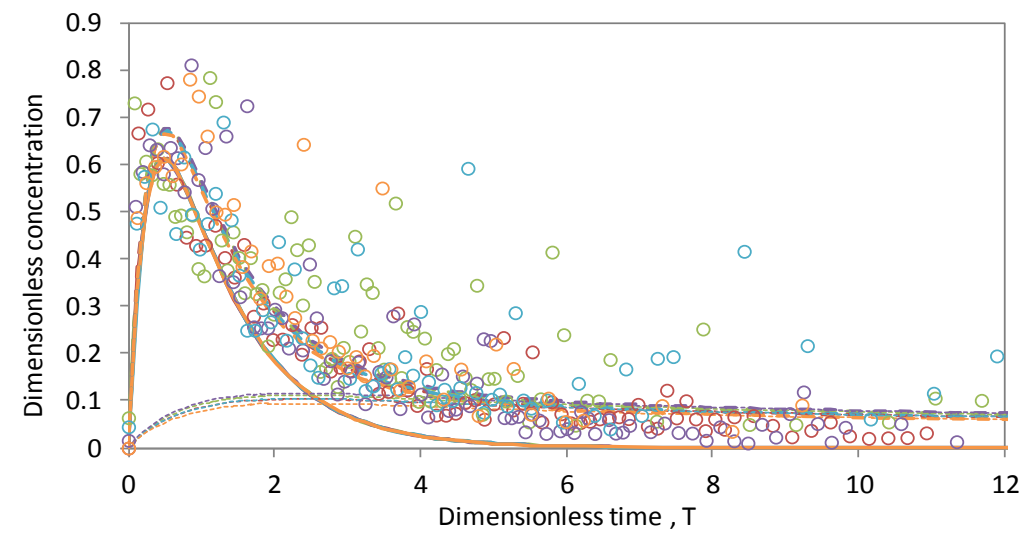

Figure 2. Dimensionless biochar erosion model (dashed lines) compared with the Hairsine-Rose model (solid lines) and the Wallach diffusion model (thin dotted lines) with the same shared parameters. Circles are measured data. Different colors represent different runs of experiment.

Table 1

Hairsine-Rose model parameters for each experiment; footnotes explain how each was determined.

\begin{tabular}{|c|c|c|c|c|c|}
\hline & Run1 & Run2 & Run3 & Run4 & Run5 \\
\hline Rainfall rate, $P\left(10^{-2} \mathrm{mms}^{-1}\right)^{\mathrm{a}}$ & 7.14 & 5.15 & 5.42 & 6.44 & 7.45 \\
\hline Ponding water depth, $D(\mathrm{~mm})^{\mathrm{a}}$ & 8.14 & 9.72 & 8.53 & 8.93 & 9.33 \\
\hline Eroded biochar, $M_{b}^{*}\left(\mathrm{mg} \mathrm{cm}^{-2}\right)^{\mathrm{b}}$ & 23.0 & 3.75 & 15.6 & 8.78 & 3.22 \\
\hline Soil detachability, a $\left(\mathrm{mg} \mathrm{l}^{-1}\right)^{\mathrm{b}}$ & 1.06 & 0.142 & 0.667 & 0.358 & 0.127 \\
\hline Soil porosity, $\boldsymbol{\theta}_{\boldsymbol{s}}^{\mathrm{a}}$ & 0.515 & 0.515 & 0.515 & 0.515 & 0.515 \\
\hline
\end{tabular}

"Directly measured, explained in details in "2. Experimental Design"

bHairsine-Rose model curve fitted, expatiated on in "3.Hairsine-Rose Model Description"

The biochar concentrations predicted by the Hairsine-Rose model effectively go to zero for $T>\sim 5$, i.e., as the shield layer is effectively fully formed (solid lines in Figure 2). The long-tail exhibited by the experimental data (symbols in Figure 2) is similar to the solute data from a similar experiment by Gao et al. $(2004,2005)$, which was explained by diffusion of solutes from deeper in the soil towards the surface. We dissected a soil column after the experimental run 3 and we dissected another soil column prepared identically to those used in our experiments and measured the biochar fractions with depth. The biochar was fairly uniformly distributed through the soil column before running the erosion experiment, but steadily increased with depth after the 
experiment (Figure 3a) similar to solutes (e.g. Ahuja and Lehman, 1983). Figure 3b-e visually illustrate the distribution of biochar in the soil after the erosion process; especially the much depleted region near the surface (i.e., light sand dominating in the shield layer) and much higher (darker) biochar concentrations deeper in the soil.

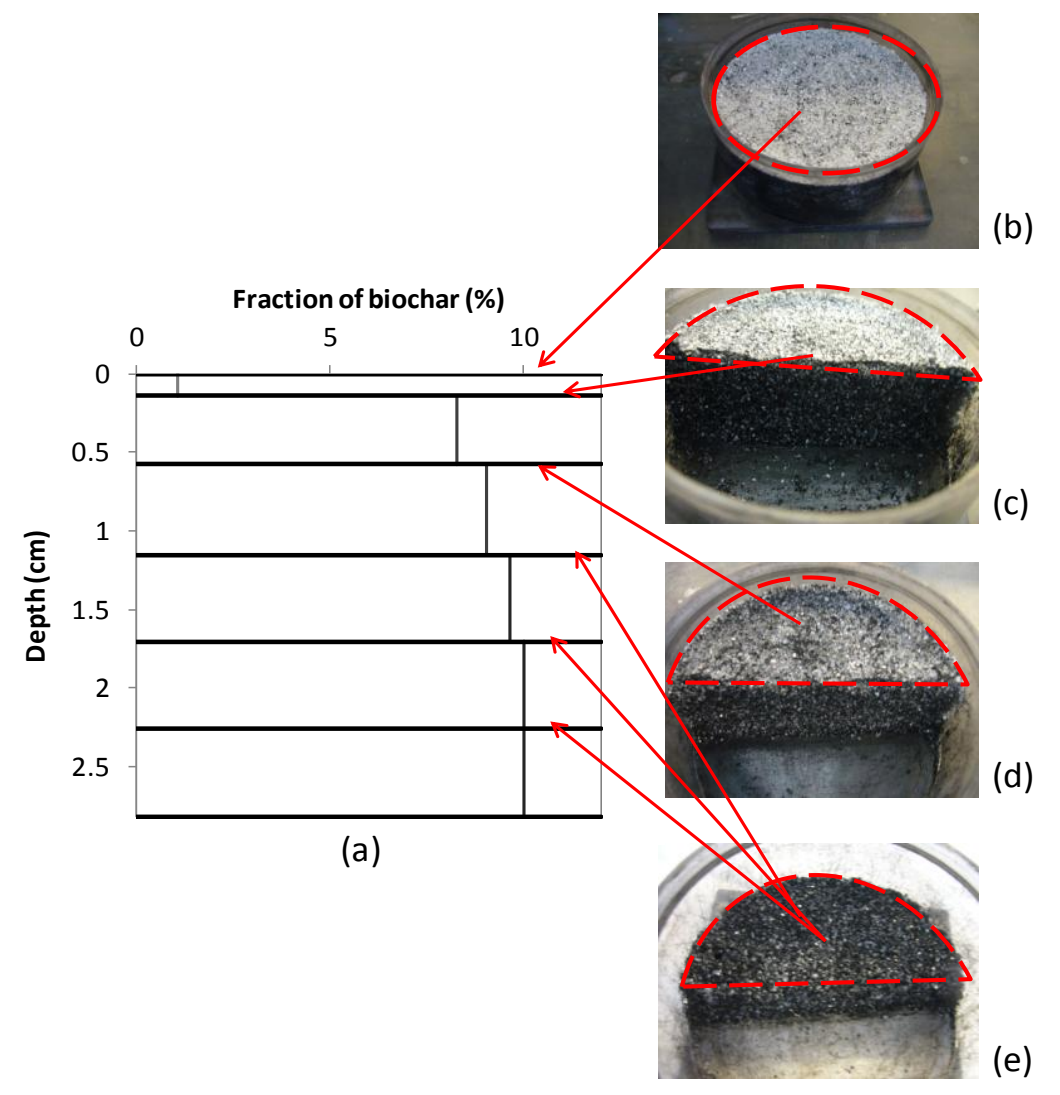

Figure 3. The graph (a) shows the fraction of biochar in saturated well mixed artificial soil after a $4 \mathrm{hr}$ erosion process. While the photos (b-e) demonstrate the shield layer surface and the interfaces between different layers after the separate experiment (4) with white sand and black biochar (9:1).

Trying to better model our experiments, we proposed coupling the Hairsine-Rose model with the Wallach et al. (1988) diffusion model:

$$
C(T)=C_{R}(T)+C_{D}(T)
$$


where $C_{R}(T)$ is dimensionless Hairsine-Rose model and $C_{D}(T)$ is dimensionless Wallach diffusion model. We adopted a dimensionless form of the Wallach diffusion model (Wallach et al., 1988):

$$
\begin{gathered}
C_{D}=\frac{c_{d}}{C_{o}}, \xi=\frac{k_{E}}{P}, w=\frac{k_{E}^{2} D}{P D_{E}} \\
C_{D}(T)=\frac{\xi}{1+w}\left[\exp (w T) \operatorname{erf} c(\sqrt{w T})-\exp (-T)+2 \sqrt{\frac{w}{\pi}} E(\sqrt{T})\right]
\end{gathered}
$$

where $c_{d}$ and $C_{D}$ are the dimensional $\left[\mathrm{M} \mathrm{L}^{-3}\right]$ and dimensionless concentrations of biochar diffused from the soil into the runoff, respectively; $C_{o}$ is the initial concentration of biochar in the soil $\left[\mathrm{M} \mathrm{L}^{-3}\right] ; \operatorname{erfc}(x)$ and $E(x)$ are the complimentary error function and Dawson's integral, respectively; $k_{E}$ is the effective mass transfer coefficient given by $k_{E}=k_{L} / R_{L}$, and $D_{E}$ is the effective diffusion coefficient given by $D_{E}=D_{S} / R_{L}$. According to Wallach et al. (1988), $D_{S}, R_{L}$, and $k_{L}$ are calculated as follow:

$$
D_{s}=\left(\theta^{10 / 3} / \theta_{s}^{2}\right) D_{w}, R_{L}=\rho_{b} K_{d}+\theta, k_{L}=0.664\left(\frac{D_{w}}{L}\right)\left(\frac{P L}{D v}\right)^{1 / 2}\left(\frac{v}{D_{w}}\right)^{1 / 3}
$$

where $D_{w}$ is the diffusion coefficient for biochar in water; $\theta$, the volumetric soil water content for our experiments was $\theta_{s}$, soil porosity, i.e. saturated volumetric soil water content (Table 1), wherever it appears, as the soil is always saturated throughout the process; $\rho_{b}$ is soil bulk density $\left[\mathrm{M} \mathrm{L}^{-3}\right] ; K_{d}$ is the ratio between immobile biochar in the soil and mobile biochar $\left[\mathrm{L}^{3} \mathrm{M}^{-1}\right]$ and is assumed to be $0 ; L$ is the slope length, taken as the radius of the soil container $(38.1 \mathrm{~mm})$; $v$ is the kinematic viscosity of water at $20^{\circ} \mathrm{C}$. 
The only parameter we curve-fitted for the Wallach diffusion item was $D_{w}$, which we assumed to be constant across all the experiments $\left(3 \times 10^{-3} \mathrm{~mm}^{2} \mathrm{~s}^{-1}\right)$. Surprisingly, it is similar in magnitude to the values Gao et al. $(2004 ; 2005)$ used for solutes. The dotted lines in Figure 2 are the dimensionless Wallach models and the dashed lines show the dimensionless superimposed Hairsine-Rose model with the Wallach diffusion model (Eq. 5). Although neither the HarisineRose model alone nor Wallach diffusion model alone predicts the erosion of biochar well, the summation of the two items simulates the measured data relatively well.

The reason why we can simulate the long-time, upward migration of biochar as a diffusion process may be that this migration is similar to the diffusion of solutes for which the Wallach diffusion model was originally developed. Solutes diffuse from high concentration regions to low concentration regions because, moving randomly, more molecules in high concentration regions migrate to low concentration regions than vice versa simply because of the difference in relative numbers of molecules. We speculate that the biochar may be migrating upward because the much denser sand particles are displacing the very low-density biochar particles and that raindrop impacts assist in this displacement. As biochar near the surface is displaced upwards, new pore-spaces become available in the shallow soil for the deeper biochar to move into and the continuation of this process results in an macro-effect that biochar particles are moving upward opposite to the concentration gradient, which explains the gradient we observed in biochar with depth in the soil column after the experiment. The observed scatter (Figure 2) may due to the discreteness and randomness of the process. We used continuous and deterministic model to capture the average, but, of course, not every raindrop dislodges the same amount of biochar 
particles from the soil matrix into the runoff: some raindrop may eject a large number of biochar particles and assist sand particles displace a number of biochar particles, while another may be much less effective in doing so.

Another mechanism for moving deep biochar upwards that we considered was buoyancy. Biochar is inherently hydrophobic due to tars and oils on its surface and its dry density is lower than water. However, we found that the biochar used here settled out of suspension although very slowly. We speculate that this is because we used very fine biochar particles and the water was able to penetrate and fill a substantial fraction of the intra-particle voids; additionally, we may have forced some water into the particles when we pumped-out the air as part of the process of saturating the soil. Larger particles appear to maintain their buoyancy more effectively (data not shown).

Even though the superposition of raindrop impact processes (Hairsine-Rose model) with diffusion-like processes (Wallach diffusion model) captured the overall patterns of biochar erosion that we observed in our experiments, our model slightly over predicted in very long-term concentrations (Figure 2). This could be an artifact due to the ponding depth, $D$, increasing slightly during the experiment as biochar was eroded out of the soil and soil water was dislodged by sand or biochar particles since raindrop impact has a jostling effect compacting the soil (i.e., the soil surface drops slightly). Of course, we assume a constant $D$ in our model. We also assumed a constant $P$, although our rain simulator was not able to maintain a perfectly constant rain intensity. We ran the model using the average ponding depth and rain intensity and compared the results using the initial ponding depth and rain intensity but there did not seem to 
be a notable difference in the modeled vs. observed biochar concentration in the runoff (Figure 4), suggesting that the model was not sensitive to these experimental difficulties. The average parameters give a slightly better prediction, which is expected, since they can accommodate both short term splash and long term "diffusion".

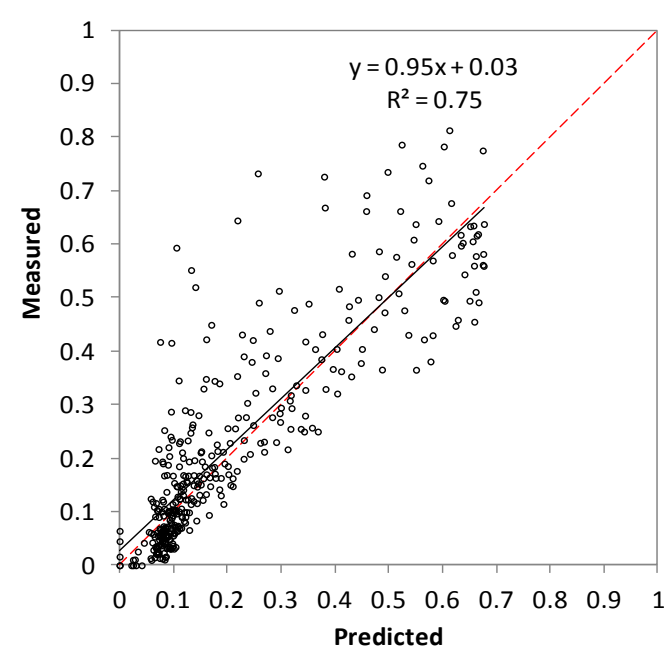

(a)

(a) (b)

Figure 4.Measured vs. predicted dimensionless concentration of biochar in the runoff: (a) using average $P$ and $D$, while (b) using initial $P$ and $D$.

Our experiments simulate biochar erosion from soil under saturated conditions with no infiltration. Our findings suggest that under similar conditions in the environment, it may be difficult to achieve long-term sequestration of biochar in soil because it may continually be migrating towards the surface. Additional experiments are needed to see if this phenomenon will occur under infiltrating conditions. Indeed, there have been field observations of biochar that appear to have migrated downward into the soil (Rumpel et al., 2009; Major et al., 2010).

\section{Conclusions}

We found that biochar erosion from saturated soil can be reasonably well modeled by superimposing models of rain-impact erosion and diffusion, similar to the way Gao et al. (2005) simulated solute exchange between soil and runoff. Here we used the Hairsine-Rose model 
(Hairsine and Rose, 1991; Heilig et al., 2001) to simulate rain-impact erosion and we used Wallach diffusion model (Wallach et al., 1988) to simulate diffusion-like processes. Our experiments were on small-scale, were level, and used a simple-structured soil (9:1 sand-biochar mixture). We are not certain of the specific mechanisms giving rise to diffusion-like movement, but we suspect that either the relatively dense sand is displacing the light biochar or that there may be buoyant forces acting on the biochar, which can be quite hydrophobic. This discovery of long-term biochar erosion may explain previous observations of preferential erosion of biochar compared to other soil constituents. Future study is recommended to more specifically identify the controlling mechanisms of the long-term biochar erosion and to how they interact with other processes including sheet flow and, infiltration. Larger scale experiments will help determine whether the findings here translate to real landscapes. Comparing biochar erosion with the erosion of clay and/or traditional fertilizer is another possible direction. 


\section{Appendix A}

Pch: proportion of biochar in the dried sand-charcoal mixture

$S a$ : mass of dried sand

Ch: mass of dried biocharl

$W$ : mass of dried sample

$R$ : mass of residual sample after combustion

$a$ : proportion of residual pure sand after combustion

$b$ : proportion of residual pure biochar after combustion

$$
\left\{\begin{array}{c}
S a+C h=W \alpha \\
S a \times a+C h \times b=R \beta
\end{array}\right.
$$

$\beta-\alpha \times a:$

$$
\begin{gathered}
S a \times a+C h \times b-S a \times a-C h \times a=R-W \times a \\
C h \times(b-a)=R-W \times a \\
C h=\frac{R-W \times a}{b-a}
\end{gathered}
$$

(A2) $-\alpha$ :

$$
\begin{gathered}
S a=W-C h=W-\frac{R-W \times a}{b-a}=\frac{W \times b-W \times a-R+W \times a}{b-a} \\
S a=\frac{W \times b-R}{b-a} \\
P c h=\frac{C h}{C h+S a} \times 100 \%
\end{gathered}
$$




\section{Appendix B}

Table B.1

Tabulated measured data: time $(t)$ in minutes and concentration of biochar $\left(c_{b}\right)$ in the runoff samples in $\mathrm{mg} / \mathrm{ml}$.

\begin{tabular}{|c|c|c|c|c|c|c|c|c|c|}
\hline \multicolumn{2}{|c|}{ Run 1} & \multicolumn{2}{|c|}{ Run 2} & \multicolumn{2}{|c|}{ Run 3} & \multicolumn{2}{|c|}{ Run 4} & \multicolumn{2}{|c|}{ Run 5} \\
\hline$t(\min )$ & $\mathrm{c}_{\mathrm{b}}(\mathrm{mg} / \mathrm{ml})$ & $t(\min )$ & $c_{b}(\mathrm{mg} / \mathrm{ml})$ & $t(\min )$ & $\mathrm{c}_{\mathrm{b}}(\mathrm{mg} / \mathrm{ml})$ & $t(\min )$ & $c_{b}(\mathrm{mg} / \mathrm{ml})$ & $t(\min )$ & $\mathrm{c}_{\mathrm{b}}(\mathrm{mg} / \mathrm{ml})$ \\
\hline 0.00 & 0.00 & 0.00 & 0.25 & 0.00 & 0.30 & 0.00 & 0.44 & 0.00 & 0.00 \\
\hline 0.25 & 18.93 & 0.25 & 2.83 & 0.25 & 9.38 & 0.25 & 4.69 & 0.25 & 1.69 \\
\hline 0.50 & 20.36 & 0.50 & 2.25 & 0.50 & 10.72 & 0.50 & 5.67 & 0.50 & 1.94 \\
\hline 0.75 & 17.14 & 0.75 & 2.35 & 0.75 & 11.76 & 0.75 & 6.65 & 0.75 & 2.06 \\
\hline 1.00 & 21.95 & 1.00 & 2.24 & 1.00 & 11.58 & 1.00 & 5.02 & 1.00 & 2.14 \\
\hline 1.25 & 15.85 & 1.25 & 2.45 & 1.25 & 10.64 & 1.25 & 0.00 & 1.25 & 1.99 \\
\hline 1.50 & 12.67 & 1.50 & 2.17 & 1.50 & 11.66 & 1.50 & 4.47 & 1.50 & 2.08 \\
\hline 1.75 & 12.17 & 1.75 & 2.16 & 1.75 & 11.26 & 1.75 & 6.07 & 1.75 & 2.70 \\
\hline 2.00 & 12.19 & 2.00 & 1.90 & 2.00 & 9.94 & 2.00 & 4.88 & 2.00 & 2.58 \\
\hline 2.25 & 13.38 & 2.25 & 1.91 & 2.25 & 14.86 & 2.25 & 4.15 & 2.25 & 2.29 \\
\hline 2.50 & 11.45 & 2.50 & 1.77 & 2.50 & 10.41 & 2.50 & 4.68 & 2.50 & 1.73 \\
\hline 2.75 & 10.27 & 2.75 & 1.91 & 2.75 & 11.65 & 2.75 & 5.31 & 2.75 & 1.71 \\
\hline 3.00 & 12.23 & 3.00 & 1.47 & 3.00 & 9.29 & 3.00 & 6.80 & 3.00 & 1.78 \\
\hline 3.25 & 7.92 & 3.25 & 1.41 & 3.25 & 6.69 & 3.25 & 4.76 & 3.25 & 1.33 \\
\hline 3.50 & 8.71 & 3.50 & 3.03 & 3.50 & 12.10 & 3.50 & 3.61 & 3.50 & 1.44 \\
\hline 3.75 & 6.52 & 3.75 & 2.84 & 3.75 & 6.45 & 3.75 & 2.46 & 3.75 & 1.10 \\
\hline 4.00 & 6.54 & 4.00 & 1.70 & 4.00 & 5.87 & 4.00 & 2.46 & 4.00 & 1.34 \\
\hline 4.25 & 7.42 & 4.25 & 1.46 & 4.25 & 13.28 & 4.25 & 2.89 & 4.25 & 1.35 \\
\hline 4.50 & 5.64 & 4.50 & 1.77 & 4.50 & 4.70 & 4.50 & 2.63 & 4.50 & 1.11 \\
\hline 4.75 & 7.24 & 4.75 & 1.56 & 4.75 & 4.66 & 4.75 & 4.30 & 4.75 & 0.96 \\
\hline 5.00 & 7.25 & 5.00 & 1.27 & 5.00 & 4.66 & 5.00 & 2.25 & 5.00 & 2.22 \\
\hline 5.25 & 4.62 & 5.25 & 1.56 & 5.25 & 5.38 & 5.25 & 3.74 & 5.25 & 0.79 \\
\hline 5.50 & 4.85 & 5.50 & 1.26 & 5.50 & 5.06 & 5.50 & 2.30 & 5.50 & 0.73 \\
\hline 5.75 & 4.65 & 5.75 & 1.30 & 5.75 & 3.88 & 5.75 & 1.73 & 5.75 & 0.78 \\
\hline 6.00 & 5.23 & 6.00 & 0.84 & 6.00 & $-^{a}$ & 6.00 & 1.48 & 6.00 & 0.71 \\
\hline 6.25 & 5.97 & 6.25 & 1.10 & 6.25 & 3.80 & 6.25 & 7.70 & 6.25 & 0.59 \\
\hline 6.50 & 3.29 & 6.50 & 1.28 & 6.50 & 7.14 & 6.50 & 3.34 & 6.50 & 0.67 \\
\hline 6.75 & 3.40 & 6.75 & 1.39 & 6.75 & 5.05 & 6.75 & 3.39 & 6.75 & 0.53 \\
\hline 7.00 & 8.11 & 7.00 & 1.89 & 7.00 & 2.70 & 7.00 & 1.45 & 7.00 & 0.68 \\
\hline 7.25 & 3.48 & 7.25 & 1.62 & 7.25 & 3.39 & 7.25 & 4.15 & 7.25 & 1.90 \\
\hline 7.50 & 2.56 & 7.50 & 1.17 & 7.50 & 2.10 & 7.50 & 1.20 & 7.50 & 0.58 \\
\hline 7.75 & 4.78 & 7.75 & 1.66 & 7.75 & 2.59 & 7.75 & 1.30 & 7.75 & 0.42 \\
\hline
\end{tabular}

Continued in next page. 
Continued Table B.1

\begin{tabular}{|c|c|c|c|c|c|c|c|c|c|}
\hline \multicolumn{2}{|c|}{ Run 1} & \multicolumn{2}{|c|}{ Run 2} & \multicolumn{2}{|c|}{ Run 3} & \multicolumn{2}{|c|}{ Run 4} & \multicolumn{2}{|c|}{ Run 5} \\
\hline $\begin{array}{c}t \\
(\min )\end{array}$ & $\begin{array}{c}\mathrm{c}_{\mathrm{b}} \\
(\mathrm{mg} / \mathrm{ml})\end{array}$ & $\begin{array}{c}t \\
(\min )\end{array}$ & $\begin{array}{c}\mathrm{c}_{\mathrm{b}} \\
(\mathrm{mg} / \mathrm{ml})\end{array}$ & $\begin{array}{c}t \\
(\min )\end{array}$ & $\begin{array}{c}\mathrm{c}_{\mathrm{b}} \\
(\mathrm{mg} / \mathrm{ml})\end{array}$ & $\begin{array}{c}t \\
(\min )\end{array}$ & $\begin{array}{c}\mathrm{c}_{\mathrm{b}} \\
(\mathrm{mg} / \mathrm{ml})\end{array}$ & $\begin{array}{c}t \\
(\min )\end{array}$ & $\begin{array}{c}\mathrm{c}_{\mathrm{b}} \\
(\mathrm{mg} / \mathrm{ml})\end{array}$ \\
\hline 8.00 & 1.98 & 8.00 & 1.36 & 8.00 & 2.98 & 8.00 & 1.57 & 8.00 & 0.45 \\
\hline 8.25 & 1.97 & 8.25 & 0.63 & 8.25 & 3.33 & 8.25 & 1.66 & 8.50 & 0.64 \\
\hline 8.50 & 2.09 & 8.50 & 0.66 & 8.50 & 1.72 & 8.50 & 1.23 & 9.00 & 0.36 \\
\hline 8.75 & 2.74 & 8.75 & 0.73 & 8.75 & 2.43 & 8.75 & 1.91 & 9.50 & 0.58 \\
\hline 9.00 & 2.90 & 9.00 & 0.50 & 9.00 & 2.97 & 9.00 & 1.52 & 10.00 & 0.24 \\
\hline 9.25 & 1.73 & 9.25 & 0.82 & 9.25 & 2.76 & 9.25 & 2.85 & 10.50 & 0.76 \\
\hline 9.50 & 2.65 & 9.50 & 0.71 & 9.50 & 5.13 & 9.50 & 1.39 & 11.00 & 0.58 \\
\hline 9.75 & 6.64 & 9.75 & 1.73 & 9.75 & 1.53 & 9.75 & 0.90 & 11.50 & 0.25 \\
\hline 10.00 & 2.29 & 10.00 & 0.96 & 10.00 & - & 10.00 & 1.23 & 12.00 & 0.37 \\
\hline 10.25 & 2.69 & 10.25 & 1.34 & 10.25 & 4.81 & 10.25 & 0.99 & 12.50 & 0.19 \\
\hline 10.50 & 5.78 & 10.50 & 1.27 & 10.50 & 2.09 & 10.50 & 1.26 & 13.00 & 0.20 \\
\hline 10.75 & 1.56 & 10.75 & 0.82 & 10.75 & 1.21 & 10.75 & 5.83 & 15.25 & 0.31 \\
\hline 11.00 & 2.78 & 11.00 & 0.65 & 11.00 & - & 11.00 & 1.16 & 17.25 & 0.12 \\
\hline 11.25 & 2.06 & 11.25 & 0.57 & 11.25 & 2.87 & 11.25 & 0.74 & 19.25 & 0.32 \\
\hline 11.50 & 1.51 & 11.50 & 2.01 & 11.50 & 1.46 & 11.50 & 1.02 & 21.25 & 0.00 \\
\hline 11.75 & 1.53 & 11.75 & 0.58 & 11.75 & 1.51 & 11.75 & 1.12 & 26.50 & 0.21 \\
\hline 12.00 & 1.61 & 12.00 & 0.99 & 12.00 & 2.79 & 12.00 & 0.87 & 31.50 & 0.22 \\
\hline 12.25 & 1.75 & 12.25 & 0.96 & 12.25 & 1.64 & 12.25 & 2.82 & 61.50 & 0.00 \\
\hline 12.50 & 1.84 & 12.50 & 0.38 & 12.50 & 2.52 & 12.50 & 1.00 & 121.50 & 0.00 \\
\hline 12.75 & 1.88 & 12.75 & 0.90 & 12.75 & 4.24 & 12.75 & 0.83 & 181.50 & 0.00 \\
\hline 13.00 & 1.77 & 13.00 & 0.38 & 13.00 & 4.17 & 13.25 & 1.00 & 241.50 & 0.00 \\
\hline 13.25 & 2.63 & 13.25 & 0.64 & 13.25 & - & 13.75 & 0.54 & & \\
\hline 13.50 & 1.32 & 13.50 & 0.38 & 13.50 & 1.18 & 14.25 & 1.35 & & \\
\hline 13.75 & 1.19 & 13.75 & 0.77 & 13.75 & 1.17 & 14.75 & 0.68 & & \\
\hline 14.00 & 3.47 & 14.00 & 0.81 & 14.00 & 1.23 & 15.25 & 0.40 & & \\
\hline 14.25 & 1.81 & 14.25 & 0.41 & 14.25 & 0.63 & 15.75 & 1.65 & & \\
\hline 14.50 & 2.84 & 14.50 & 0.58 & 14.50 & 1.32 & 16.25 & 0.68 & & \\
\hline 14.75 & 1.75 & 14.75 & 0.48 & 14.75 & 1.08 & 16.75 & 1.87 & & \\
\hline 15.00 & 1.05 & 15.00 & 1.33 & 15.00 & 0.57 & 17.25 & 1.91 & & \\
\hline 15.25 & 1.75 & 15.25 & 0.28 & 15.25 & - & 19.50 & 4.10 & & \\
\hline 15.50 & 1.13 & 15.50 & 0.57 & 15.50 & 0.67 & 21.50 & 2.14 & & \\
\hline 15.75 & 1.88 & 15.75 & 0.57 & 15.75 & 0.75 & 23.50 & 0.60 & & \\
\hline 16.25 & 1.95 & 16.25 & 0.39 & 16.00 & 0.60 & 25.50 & 1.14 & & \\
\hline 16.75 & 1.36 & 16.75 & 0.59 & 16.25 & 1.41 & 27.50 & 1.92 & & \\
\hline 17.25 & 0.67 & 17.25 & 0.21 & 16.50 & 1.17 & 32.75 & 1.17 & & \\
\hline 17.75 & 1.06 & 17.75 & 0.40 & 16.75 & 0.56 & 37.75 & 1.22 & & \\
\hline
\end{tabular}

Continued in next page. 


\section{Continued Table B.1}

\begin{tabular}{|c|c|c|c|c|c|c|c|c|c|}
\hline \multicolumn{2}{|c|}{ Run 1} & \multicolumn{2}{|c|}{ Run 2} & \multicolumn{2}{|c|}{ Run 3} & \multicolumn{2}{|c|}{ Run 4} & \multicolumn{2}{|c|}{ Run 5} \\
\hline $\begin{array}{c}\mathrm{t} \\
(\mathrm{min})\end{array}$ & $\begin{array}{c}\mathrm{c}_{\mathrm{b}} \\
(\mathrm{mg} / \mathrm{ml})\end{array}$ & $\begin{array}{c}\mathrm{t} \\
(\min )\end{array}$ & $\mathrm{c}_{\mathrm{b}}(\mathrm{mg} / \mathrm{ml})$ & $t(\min )$ & $\mathrm{c}_{\mathrm{b}}(\mathrm{mg} / \mathrm{ml})$ & $\begin{array}{c}\mathrm{t} \\
(\min )\end{array}$ & $\mathrm{c}_{\mathrm{b}}(\mathrm{mg} / \mathrm{ml})$ & $t(\min )$ & $c_{b}(\mathrm{mg} / \mathrm{ml})$ \\
\hline 18.25 & 1.56 & 18.25 & 1.60 & 17.00 & - & 67.50 & 0.41 & & \\
\hline 18.75 & 0.73 & 18.75 & 0.93 & 17.25 & 1.10 & 127.50 & 0.25 & & \\
\hline 19.25 & 0.58 & 19.25 & 0.19 & 17.50 & 0.58 & 187.50 & 0.11 & & \\
\hline 19.75 & 0.62 & 19.75 & 0.39 & 17.75 & 0.62 & 247.50 & 0.10 & & \\
\hline 20.25 & 0.63 & 20.25 & 0.39 & 18.00 & 0.88 & & & & \\
\hline 20.75 & 0.91 & 20.75 & 0.72 & 18.25 & - & & & & \\
\hline 23.00 & 0.41 & 22.75 & 0.22 & 18.75 & 0.63 & & & & \\
\hline 25.00 & 0.82 & 24.75 & 0.97 & 19.25 & 0.97 & & & & \\
\hline 27.00 & 1.21 & 26.75 & 0.19 & 19.75 & 0.60 & & & & \\
\hline 29.00 & 0.28 & 28.75 & 0.19 & 20.25 & 0.58 & & & & \\
\hline \multirow[t]{21}{*}{31.00} & 0.38 & 30.75 & - & 20.75 & 0.30 & & & & \\
\hline & & 32.75 & 0.21 & 21.25 & 0.82 & & & & \\
\hline & & 34.75 & 0.41 & 21.75 & 0.28 & & & & \\
\hline & & 36.75 & 0.39 & 22.25 & 0.19 & & & & \\
\hline & & 38.75 & 0.40 & 22.75 & 0.92 & & & & \\
\hline & & & & 23.25 & 0.42 & & & & \\
\hline & & & & 23.75 & 1.34 & & & & \\
\hline & & & & 24.25 & 2.18 & & & & \\
\hline & & & & 24.75 & 0.95 & & & & \\
\hline & & & & 25.25 & 0.23 & & & & \\
\hline & & & & 25.75 & 0.80 & & & & \\
\hline & & & & 27.75 & 0.95 & & & & \\
\hline & & & & 29.75 & 0.25 & & & & \\
\hline & & & & 31.75 & 0.67 & & & & \\
\hline & & & & 33.75 & 0.39 & & & & \\
\hline & & & & 35.75 & 0.58 & & & & \\
\hline & & & & 37.75 & 0.41 & & & & \\
\hline & & & & 39.75 & 0.64 & & & & \\
\hline & & & & 41.75 & 0.98 & & & & \\
\hline & & & & 43.75 & 2.00 & & & & \\
\hline & & & & 45.75 & 1.07 & & & & \\
\hline
\end{tabular}

The symbol "-" represents missing data, caused by accidently touching the soil surface with pipette tip when extracting the sample. 


\section{REFERENCES}

Ahuja, L.R., Lehman, O.R., 1983. The extent and nature of rainfall-soil interaction in the release of soluble chemicals to runoff. J. Environ. Qual. 12(1), 34-40.

Beesley, L., Moreno-Jiménez, E., Gomez-Eyles, J.L., 2010. Effects of biochar and greenwaste compost amendments on mobility, bioavailability and toxicity of inorganic and organic contaminants in a multi-element polluted soil. Environ. Pollut. 158(6), 2282-2287.

Chan, K.Y., Van Zwieten, L., Meszaros, I., Downie, a., Joseph, S., 2007. Agronomic values of greenwaste biochar as a soil amendment. Aust. J. Soil Res. 45(8), 629-629.

Chen, B., Yuan, M., 2011. Enhanced sorption of polycyclic aromatic hydrocarbons by soil amended with biochar. J. Soils. Sediment. 11(1), 62-71.

Cheng, C.-H., Lehmann, J., 2009. Ageing of black carbon along a temperature gradient. Chemosphere 75(8), 1021-1027.

Cheng, C.-H., Lehmann, J., Thies, J.E., Burton, S.D., 2008. Stability of black carbon in soils across a climatic gradient. J. Geophys. Res.-Biogeosci. 113(G2).

Elad, Y. et al., 2010. Induction of systemic resistance in plants by biochar, a soil-applied carbon sequestering agent. Phytopathol. 100(9), 913-921.

Foereid, B., Lehmann, J., Major, J., 2011. Modeling black carbon degradation and movement in soil. Plant Soil 345(1-2), 223-236.

Gao, B., Todd Walter, M., Steenhuis, T.S., Hogarth, W.L., Parlange, J.Y., 2004. Rainfall induced chemical transport from soil to runoff: Theory and experiments. J. Hydrol. 295(1-4), 291304.

Gao, B. et al., 2003. Investigating ponding depth and soil detachability for a mechanistic erosion model using a simple experiment. J. Hydrol. 277(1-2), 116-124.

Gao, B. et al., 2005. Investigating raindrop effects on transport of sediment and non-sorbed chemicals from soil to surface runoff. J. Hydrol. 308(1-4), 313-320.

Glaser, B., Lehmann, J., Zech, W., 2002. Ameliorating physical and chemical properties of highly weathered soils in the tropics with charcoal - a review. Biol. Fertil. Soil. 35(4), 219-230.

Hairsine, P.B., Rose, C.W., 1991. Rainfall detachment and deposition: Sediment transport in the absence of flow-driven processes. Soil Sci. Soc. Am. J. 55(2), 320-324.

Heilig, a. et al., 2001. Testing a mechanistic soil erosion model with a simple experiment. J. Hydrol. 244(1-2), 9-16. 
Kookana, R.S., 2010. The role of biochar in modifying the environmental fate, bioavailability, and efficacy of pesticides in soils: A review. Aust. J. Soil Res. 48(6-7, SI), 627-637.

Lehmann, J., 2007. A handful of carbon. Nature 447(7141), 143-144.

Lehmann, J., Gaunt, J., Rondon, M., 2006. Bio-char sequestration in terrestrial ecosystems - a review. Mitig. Adapt. Strateg. Global Change 11(2), 395-419.

Major, J., Lehmann, J., Rondon, M., Goodale, C., 2010. Fate of soil-applied black carbon: Downward migration, leaching and soil respiration. Global Change Biol. 16(4), 13661379.

Nguyen, B.T., Lehmann, J., Hockaday, W.C., Joseph, S., Masiello, C.A., 2010. Temperature sensitivity of black carbon decomposition and oxidation. Environ. Sci. Technol. 44(9), 3324-3331.

Nguyen, B.T. et al., 2008. Long-term black carbon dynamics in cultivated soil. Biogeochem. 89(3), 295-308.

Rondon, M.A., Lehmann, J., Ramirez, J., Hurtado, M., 2007. Biological nitrogen fixation by common beans (phaseolus vulgaris 1.) increases with bio-char additions. Biol. Fertil. Soil. 43(6), 699-708.

Rumpel, C. et al., 2006a. Black carbon contribution to soil organic matter composition in tropical sloping land under slash and burn agriculture. Geoderma 130(1-2), 35-46.

Rumpel, C., Ba, a., Darboux, F., Chaplot, V., Planchon, O., 2009. Erosion budget and process selectivity of black carbon at meter scale. Geoderma 154(1-2), 131-137.

Rumpel, C. et al., 2006b. Preferential erosion of black carbon on steep slopes with slash and burn agriculture. Catena 65(1), 30-40.

Singh, B., Singh, B.P., Cowie, A.L., 2010. Characterisation and evaluation of biochars for their application as a soil amendment. Aust. J. Soil Res. 48(6-7, SI), 516-525.

Uchimiya, M., Lima, I.M., Klasson, K.T., Wartelle, L.H., 2010. Contaminant immobilization and nutrient release by biochar soil amendment: Roles of natural organic matter. Chemosphere 80(8), 935-940.

Wallach, R., Jury, W.a., Spencer, W.F., 1988. Transfer of chemicals from soil solution to surface runoff: A diffusion-based soil model. Soil Sci. Soc. Am. J. 52(3), 612-612.

Yu, X.-Y., Ying, G.-G., Kookana, R.S., 2009. Reduced plant uptake of pesticides with biochar additions to soil. Chemosphere 76(5), 665-671. 